\title{
GMR
}

\section{Molecular characterization, tissue expression profile and SNP analysis of porcine GLP2R}

\author{
Y.L. Chai, H.M. Ma and J. Jiang \\ College of Animal Science and Technology of Hunan Agricultural University, \\ Changsha, China \\ Corresponding authors: H.M. Ma / J. Jiang \\ E-mail: mahaiming2000@163.com / jiangjun1121@126.com \\ Genet. Mol. Res. 14 (4): 12931-12941 (2015) \\ Received May 25, 2015 \\ Accepted August 11, 2015 \\ Published October 21, 2015 \\ DOI http://dx.doi.org/10.4238/2015.October.21.14
}

ABSTRACT. Glucagon-like peptide-2 receptor (GLP2R), a member of the G-protein-coupled receptor family, plays an important role in intramuscular fat formation. Little is known, however, about porcine GLP2R. In the present study, GLP2R was cloned, and its expression in pig muscle characterized. By rapid amplification of cDNA ends, gene sequence was obtained from Shaziling pigs. Full-length cDNA was 1868 bp, including an open reading frame $1665 \mathrm{bp}$ in length, encoding 554 amino acids, and $203 \mathrm{bp}$ at the 3 ' end. The GLP2R homology between porcine and other species was performed using bioinformatics techniques to construct a phylogenetic tree. Porcine GLP2R was most closely related to those from Orcinus orca and Ovis aries, and most distantly related to those from Chrysemys picta, Taeniopygia guttata, and Falco peregrinus. Real-time PCR analysis showed expression of porcine GLP2R in 10 different tissues from 25-dayold Yorkshire and Shaziling piglets, with expression levels being highest in the longissimus dorsi muscle and lowest in kidney. For each pig breed, expression level in longissimus dorsi muscle was highest among ten tissues $(P<0.05)$. Between the two breeds, GLP2R expression levels were significant in pancreas, the crureus and longissimus dorsi muscles $(P<0.05)$. A single SNP of porcine GLP2R, A343G, was identified, and 
genotypes were determined by PCR-RFLP. This study provides an insight into the function of GLP2R in swine.

Key words: Pig; Expression profiles; Single nucleotide polymorphism; GLP2R; Cloning

\section{INTRODUCTION}

Glucagon-like peptide-2 (GLP2) is a recently-discovered intestinal epithelium specific growth factor that contributes to intestinal growth and development (Jiang et al., 2008; Hsieh et al., 2009), intestinal mucosal pathological damage repair (Wu et al., 2010), and intestinal barrier function (Moadebi et al., 2007; Yazbeck et al., 2009; Jiang et al., 2012). Additionally, GLP2 is involved in the inhibition of intestinal cell apoptosis (Burrin et al., 2005); enhancement of intestine transport; and absorption of nutrients (Petersen et al., 2003; J de Heer et al., 2007; Han and Zou, 2010).

Glucagon-like peptide-2 receptor (GLP2R) is a member of the G-protein-coupled receptor family (Qiu and Chen, 2013; Mo et al., 2014) and is highly homologous to glucagonlike peptide-1 (GLP1R), glucagon (GCG), and glucose-dependent insulinotropic polypeptide $(G I P)$ receptors (Park et al., 2013). As a specific binding receptor for GLP2, GLP2R also plays a regulatory role in intestinal mucosal cell proliferation, differentiation and repair (Taylor-Edwards et al., 2010). Luo et al. (2012) demonstrated that GLP2R played a role in porcine intramuscular fat, which was one of the major parameters influencing meat quality characteristics (Fernandez et al., 1999; Suzuki et al., 2005; Wood et al., 2008). Consumer demand for high quality meat is increasing (Gao and Zhao, 2009; Gjerlaug-Enger et al., 2010). However, over the past few decades, breeding programs of swine have focused on production of carcasses with high lean meat and extremely low fat, resulting in considerably decreased intramuscular fat (IMF) content (Cameron et al., 1990; Grindflek et al., 2001). Recently, there have been enormous endeavors to improve meat quality by enhancing IMF content. A number of genes have been reported to be associated with IMF of pork, such as FAPB3, LEPR, and LDLR (Li et al., 2011; Serao et al., 2011). It would therefore appear that an understanding of the molecular mechanisms of fat accumulation is important in improving IMF content of pork.

GLP2R is located on porcine chromosome 12, mouse chromosome 11, and human chromosome 17. To date, GLP2R cloning and expression has been achieved for rat, human and mouse (Shin et al., 2005); studies of porcine GLP2R are rarely reported. In the current study, porcine GLP2R cDNA was cloned using the rapid amplification CDNA ends (RACE) technique (Yeku and Frohman, 2011). Bioinformatics and phylogenetic tree analyses were performed based on porcine GLP2R amino acid sequence, and real-time quantitative PCR (Winer et al., 1999; Jin et al., 2013) was adopted to inspect GLP2R expression patterns in ten tissue types from two pig breeds. The purpose of the study is to lay a foundation for the study of GLP2R gene in the formation of IMF in the porcine.

\section{MATERIAL AND METHODS}

\section{Sample collection}

The ear tissue samples were from Ningxiang $(N=62)$, Shaziling $(N=25)$, Daweizi $(N=$ 45), Taoyuan black $(N=74)$, and Yorkshire $(N=293)$. Three Shazhiling and three Yorkshire pigs 
are all aged 25 days for real-time quantitative PCR. Ten tissues from each breed were collected, including longissimus dorsi, crureus muscle, lung, liver, pancreas, intestine, cecum, heart, spleen, and kidney. Samples were immediately snap-frozen by liquid nitrogen and stored at $-80^{\circ} \mathrm{C}$ until further processing. Pig genomic DNA was extracted from five different breeds, using the phenol/ chloroform method.

\section{RNA extraction, reverse transcription, cloning and sequencing}

Total RNA was extracted from the longissimus dorsi of Shaziling pigs using the total RNA extraction kit in accordance with manufacturer instructions. The RNA quality and concentration were evaluated for each sample using a Nanodrop 2000 spectrophotometer. Total RNA was treated with DNase I and then first-strand cDNA was synthesized using the SUPERSCRIPT II RT Reverse Transcription System kit, following the manufacturer protocol (Invitrogen, USA). The conditions for PCR amplification were based on human GLP2R mRNA (GenBank No.: NM_004246) and were $94^{\circ} \mathrm{C}$ for $5 \mathrm{~min} ; 32$ cycles of $94^{\circ} \mathrm{C}$ for $20 \mathrm{~s}, 59^{\circ} \mathrm{C}$ for $25 \mathrm{~s}$, and $72^{\circ} \mathrm{C}$ for $30 \mathrm{~s}$; and $72^{\circ} \mathrm{C}$ for $5 \mathrm{~min}$. Amplified products were purified on a gel, then cloned into pMD19-T vector (Takara, Japan) and sequenced.

\section{Rapid amplification of cDNA ends (RACE)}

To obtain full length GLP2R cDNA, two primer pairs were designed to amplify 5 ' and 3 ' ends of the gene, based on the coding sequence (CDS) obtained for porcine GLP2R. Using SMART TM RACE cDNA Amplification Kit, 5'-RACE and 3'-RACE PCR were performed according to the manufacturer protocol (BD Science, USA). Gene-specific primers (GSPs), universal primer (UPM), and abridged universal amplification primer (AUAP) were presented in Table 1. Amplified products were separated on an agarose $1.5 \%(\mathrm{w} / \mathrm{v}) \mathrm{gel}$. Following gel purification, products were cloned into the vector pMD19-T (Takara, Japan) and sequenced. Full-length cDNA sequence was assembled using DNAStar 7.1 software (Madison, Wisconsin, USA). Alignment of porcine cDNA with the sequence published in GenBank (National Center Biology Information, NCBI) was performed using the online software Basic Local Alignment Searching Tool (BLAST) (http://blast. ncbi.nlm.nih.gov/Blast.cgi).

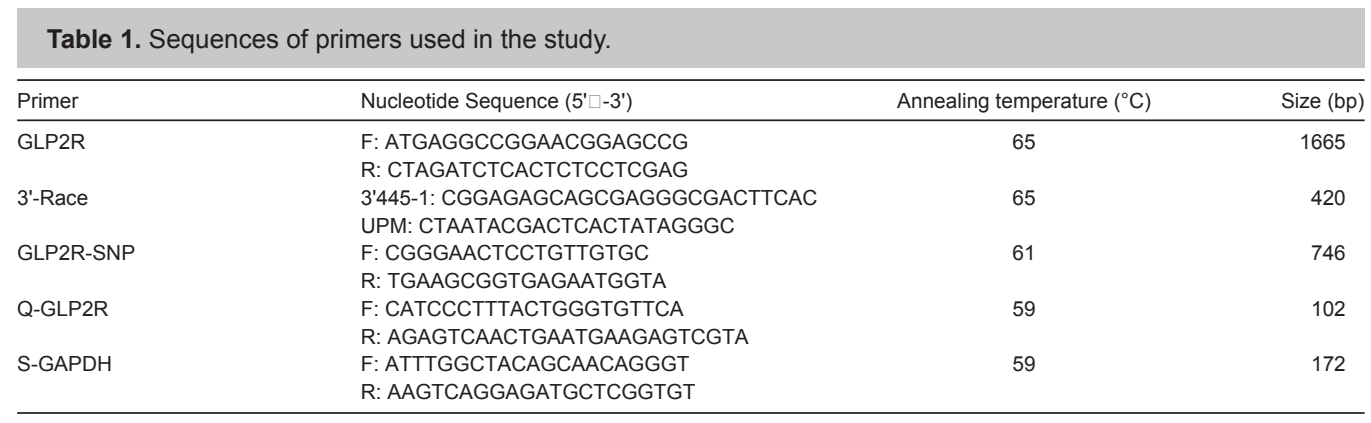

\section{Bioinformatic analysis}

Physical and chemical properties of porcine GLP2R were analyzed using DNAstar 7.1 software. Nucleotide (nt) sequence analysis and amino acid (aa) sequence deduction were 
performed using the Expert Protein Analysis System (http://www.expasy.org/). Protein domain features were predicted using the simple modular architecture tool (http://smart.embl-heidelberg. de/). Porcine GLP2R sequence was compared with sequence from 12 different species using DNAMAN V6 software, which was also utilized to align the aa sequences of GLP2R. A phylogenetic tree was constructed with the full-length cDNA sequences of previously published $G L P 2 R$, using the neighbor-joining (NJ) method with MEGA version 5.0 (Tamura et al., 2011).

\section{Real-time quantitative PCR (qPCR) analysis}

Expression of porcine GLP2R gene was evaluated by real-time quantitative PCR (qRT-PCR). Isolation of RNA was carried out using an RNA extraction kit, following the manufacturer instructions (Qiagen, Dalian, China). Total cDNA was generated using the QuantiTect Transcription Kit (Qiagen, Dalian, China). Real-time PCR was carried out in the Real-time PCR System (ABI) with SYBR Green primers using Premier 5.0 software (Table 1). Glyceraldehyde 3-phosphate dehydrogenase (GAPDH) was an internal control gene, and gene expression levels were calculated using the $2^{-\Delta \Delta C t}$ comparative $\mathrm{CT}$ method. Amplification reactions were carried out in a final volume of $20 \mu \mathrm{L}$ comprising $10 \mu \mathrm{L} 2 \mathrm{X}$

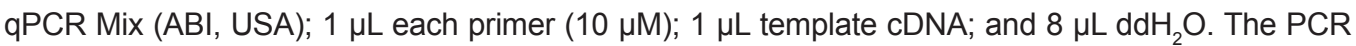
conditions were $95^{\circ} \mathrm{C}$ for $2 \mathrm{~min} ; 40$ cycles of $95^{\circ} \mathrm{C}$ for $30 \mathrm{~s}$ and $60^{\circ} \mathrm{C}$ for $40 \mathrm{~s}$; and $72^{\circ} \mathrm{C}$ for $30 \mathrm{~s}$. Using statistical software SAS10.0 for statistical analysis, significance differences of porcine GLP2R gene among different tissues and different breeds of pigs was analyzed (Figure 5). Porcine GLP2R mRNA expression levels were highest in longissimus dorsi muscle and expression levels differed significantly $(P<0.05)$ between tissues. Kidney and lung had the lowest expression and differences were also significant $(P<0.05)$ with other tissues.

\section{SNP identification and allele frequency analysis}

Primers GLP2R-SNP (Table 1) were used for detecting SNP in five different breeds. Genotyping was performed by PCR-RFLP technique using BstE II restriction enzyme (Fermentas, Beijing, China). The PCR products were digested by incubation at $37^{\circ} \mathrm{C}$ for $10 \mathrm{~h}$ in $20 \mu \mathrm{L}$ reaction mixture containing 9.8 $\mu \mathrm{L}$ PCR products; $8 \mu \mathrm{L}$ nuclease-free water; $2 \mu \mathrm{L}$ 10X Buffer Tango; and 0.2 $\mu \mathrm{L} 10 \cup$ BstE II. Restriction fragments were analyzed on a $2.0 \%$ agarose (w/v) gel.

\section{RESULTS}

\section{Sequence analysis and comparison of amino acid sequence homology between porcine and other mammalian GLP2R}

Assembly of the middle segment and 3'-RACE sequence resulted in a $1868 \mathrm{bp}$ length cDNA sequence, which was submitted to GenBank (accession No. KF636493). The sequence comprised 203 bp of a 3'-untranslated region (UTR) as well as 1665 bp of an open reading frame (ORF) encoding 554 aa (Figure 1). Analysis of the ORF sequence demonstrated that the encoded protein had an approximate molecular weight of $62.96 \mathrm{kDa}$, and a theoretical isoelectric point PI of 9.279 (slightly alkaline). Results of Smart prediction demonstrated that along porcine GLP2R, aa residues 92 to 168 represented a hormone receptor (HormR) domain, while aa residues 176 to 433 represented PFAM: 7tm_2 domain (Figure 2). In addition, three pieces of low complexity sequence were noted at aa residues. The aa 188-204 was a low complexity for 
SLSTASLFLALTLLLCL sequence; aa 334-345 sequence was NNRNKNIWWIIR; and 256-371 sequence was FFIFLKILKLLISKLK.

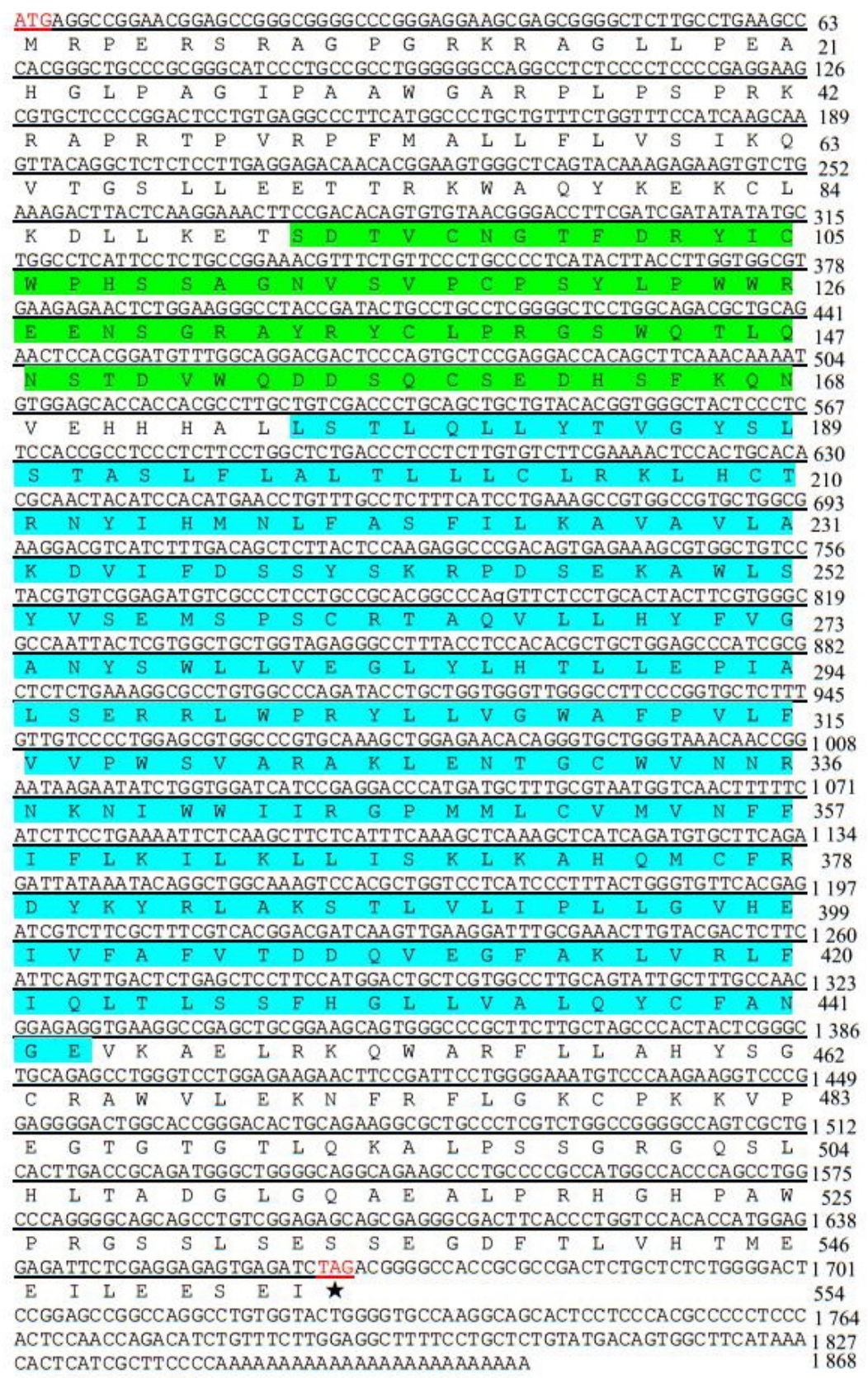

Figure 1. Nucleotide and amino acid sequence of porcine GLP2R Open reading frame (ORF) of GLP2R nucleotide sequence is underlined. The stop codon is marked with a star, and start and stop codons are shaded in red. The HormR domain is shaded with green and PFAM: $7 \mathrm{tm} \_2$ domain is shaded with blue. 


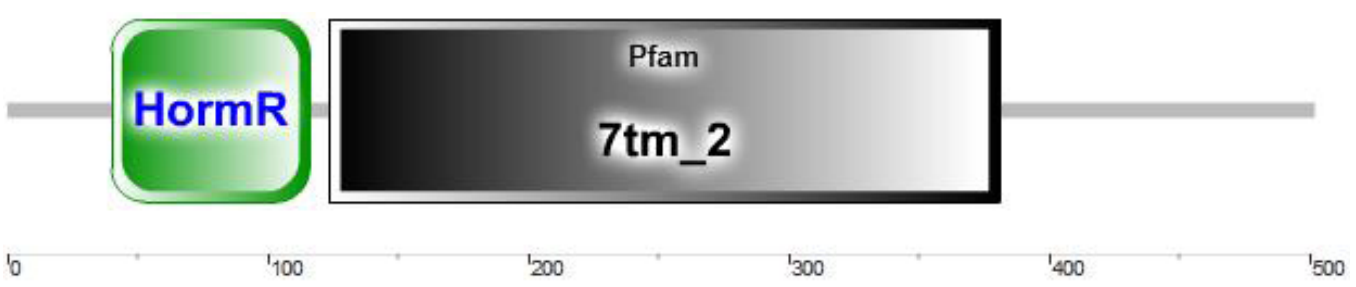

Figure 2. $G L P 2 R$ conservative structure domain analysis.

Nucleotide sequence homology was compared between GLP2R from pig and 12 other species from the NCBI database, such as(Taeniopygia guttata (Zebra finch), Trichechus manatus latirostris (Florida manatee), Orcinus orca (Orca), Felis catus (Domestic cat), Ovis aries (Sheep), Mus musculus (mouse), Dasypus novemcinctus (Peba), Tursiops truncatus (Atlantic bottlenose dolphin), Homo sapiens (human), Chrysemys picta bellii (painted turtle), Falco peregrinus (peregrine), Equus caballus (horse). Results were shown in Table 2. Pig GLP2R nt sequence was most homologous to GLP2R of Orcinus orca $(87.37 \%)$, and least homologous to GLP2R of Chrysemys picta bellii $(60.25 \%)$. Results of homology analysis of deduced aa sequence were similar to those of nt analysis (Figure 3 ).

Table 2. GenBank version of GLP2R nucleotide sequence in different species and levels of homology.

\begin{tabular}{llcc}
\hline Species & GenBank Version & Nucleotide Homology (\%) & Amino Acid Homology (\%) \\
\hline Taeniopygia guttata & XM_002187228.2 & 60.95 & 54.80 \\
Trichechus manatus latirostris & XM_004375982.1 & 82.27 & 77.12 \\
Orcinus orca & XM_004266843.1 & 87.37 & 83.57 \\
Felis catus & XM_003996288.1 & 82.24 & 79.54 \\
Ovis aries & XM_004013306.1 & 85.89 & 81.41 \\
Mus musculus & NM_175681.3 & 77.52 & 73.40 \\
Dasypus novemcinctus & XM_004460224.1 & 76.58 & 64.57 \\
Tursiops truncatus & XM_004313506.1 & 73.66 & 64.08 \\
Homo sapiens & NM_004246.1 & 82.06 & 76.71 \\
Chrysemys picta bellii & XM_005305108.1 & 60.25 & 56.39 \\
Falco peregrinus & XM_005243602.1 & 59.79 & 56.29 \\
Equus caballus & XM_001503249.2 & 84.63 & 80.51 \\
\hline
\end{tabular}

\section{Phylogenetic analysis}

A phylogenetic tree was constructed from multiple alignments of the deduced aa sequences of porcine GLP2R, with the corresponding isoform sequences of other animals (Figure 4). Pigs had the closest genetic relationships to Orcinus orca and Ovis aries, and more distant genetic relationships to Chrysemys picta bellii, Falco peregrinus, and Taeniopygia guttata.

\section{Tissue expression pattern of porcine GLP2R}

Results are summarized in Figure 5. A contrario sensus analysis showed that expression levels in longissimus dorsi muscle differed significantly between the two pig breeds $(P<0.01)$ as did expression levels in pancreas and crureus muscle (both $P<0.05$ ), while the differences in small intestine, cecum, heart, kidney, liver, lung, spleen was not significant between the pig breeds $(P>0.05)$. 

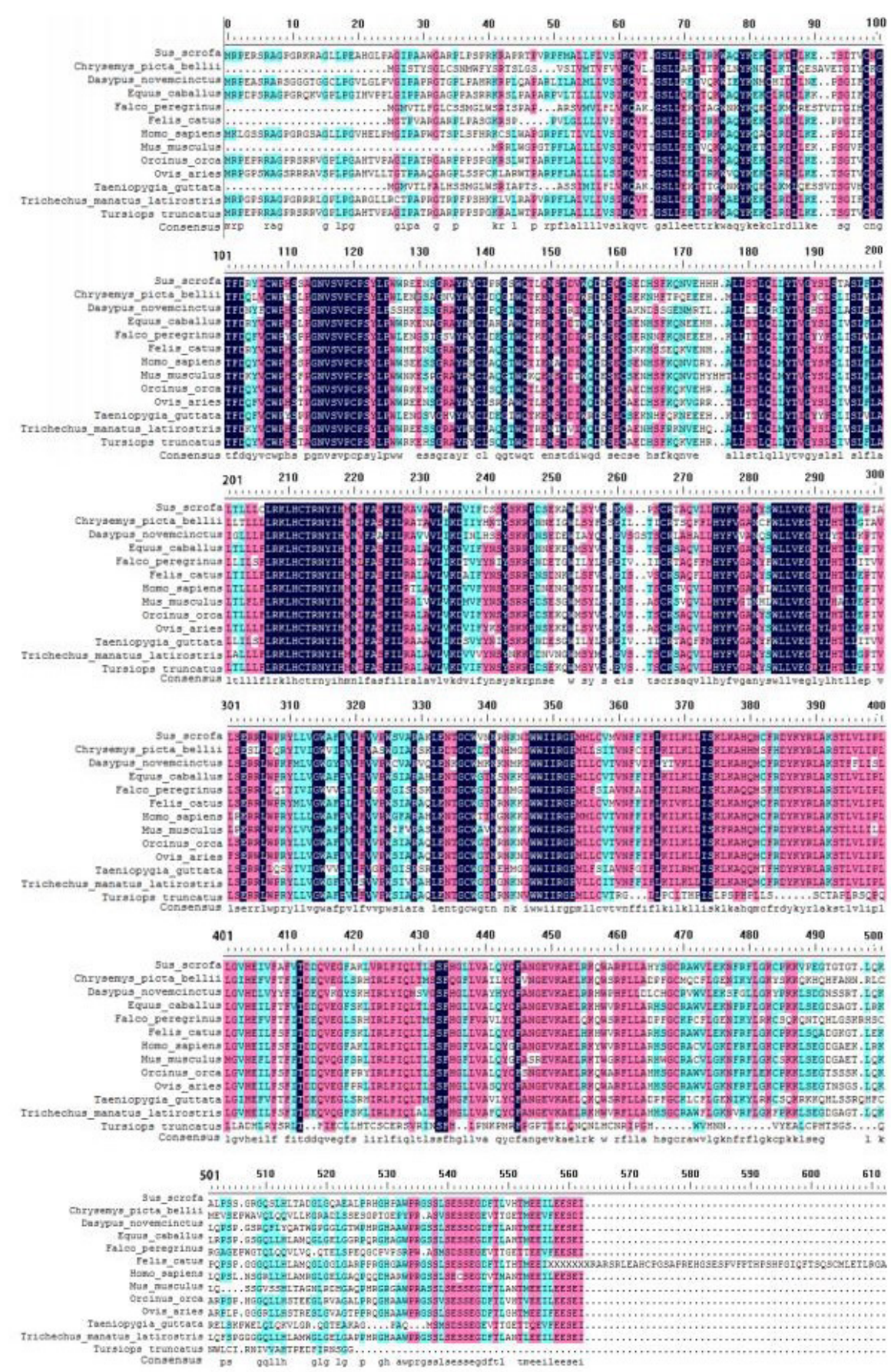

Figure 3. Amino acid sequence alignment of the GLP2R gene from different species Levels of amino acid sequence similarity to GLP2R from different species are classified as follows: high (navy blue shading), intermediate (pink shading), and low (blue-green). 


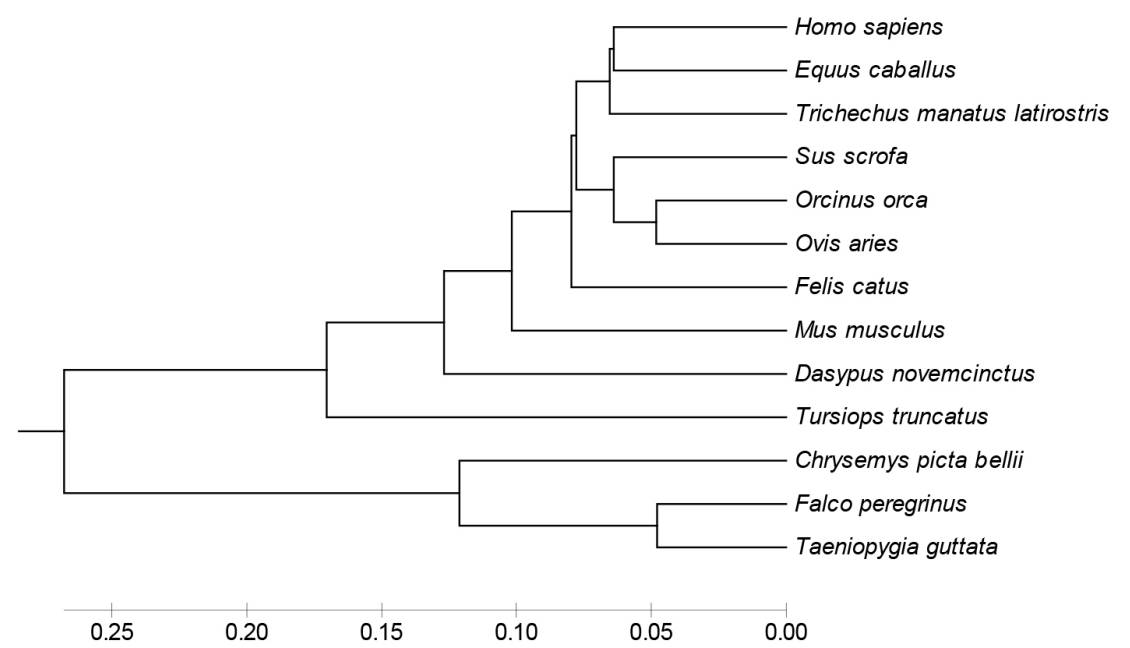

Figure 4. Phylogenetic tree based on amino acid sequences of GLP2R.

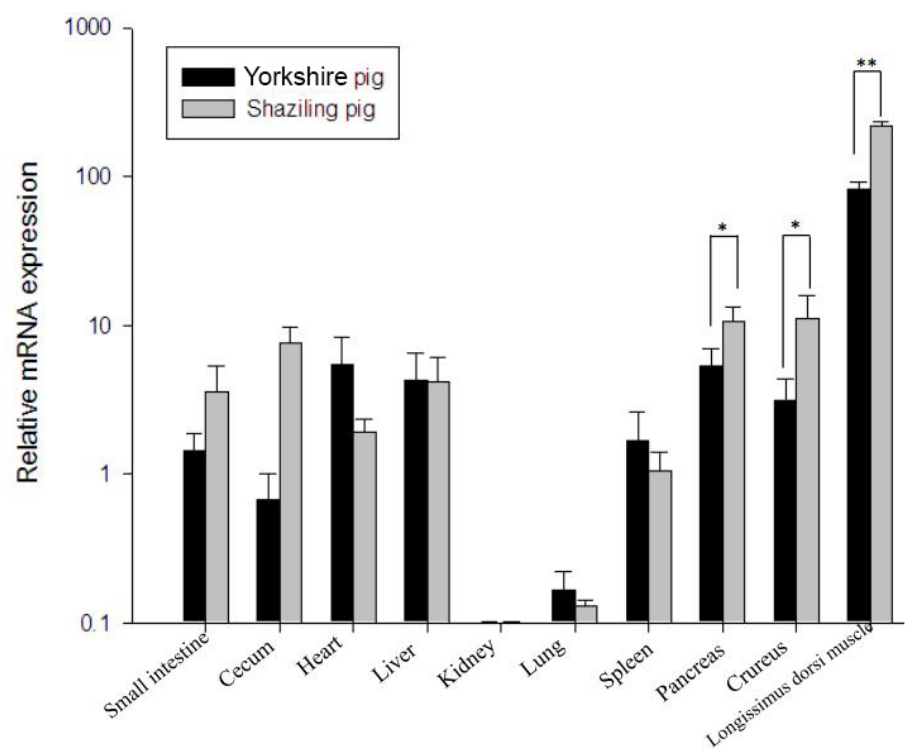

Figure 5. Expression of pig GLP2R mRNA by tissue type and pig breed '*' is $P<0.05$; “**' is $P<0.01$.

\section{Polymorphism detection and allele frequency}

A polymorphism was detected using the primer GLP2R-SNP. There was a nt substitution from $A$ to $G$ at the position 243 of the amplified fragment (Figure 6). Three genotypes for the polymorphism, $G G, G A$ and $A A$, were generated. The results showed that allele $G$ was predominant in Chinese native pig breeds (Ningxiang, Shaziling, Daweizi and Taoyuan Black breeds), while $A$ was predominant in Yorkshire (Table 3). 


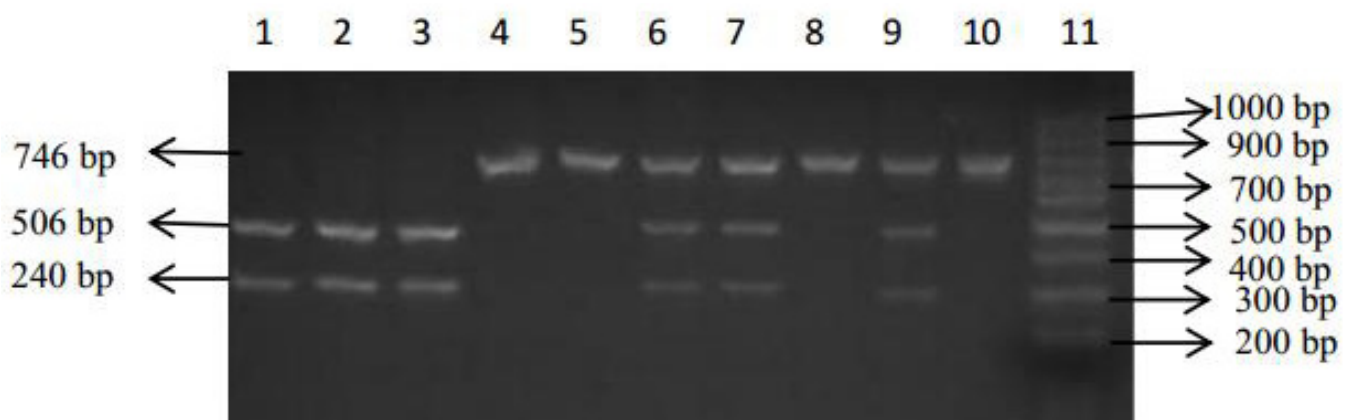

Figure 6. The electrophoresis patterns obtained digestion with BstEll endonuclease Lanes 1-3, GG genotype; Lanes 3, 4, 8, and 10, AA genotype; Lanes 6, 7, and 9, AG genotype; M: 100 bp DNA Ladder Marker.

Table 3. Genotype distributions and allele frequencies of GLP2R BstEll genotype in five pig breeds.

\begin{tabular}{lcrrrrr}
\hline Breed & Sample size & \multicolumn{3}{c}{ Genotype frequency } & & \multicolumn{2}{c}{ Allele frequency } \\
\cline { 3 - 6 } & & $G G$ & $A G$ & $A A$ & & $G$ \\
\hline Ningxiang & 62 & 62 & 0 & 0 & 1.0000 & 0.0000 \\
Shaziling & 25 & 3 & 21 & 1 & 0.5400 & 0.4600 \\
Daweizi & 45 & 51 & 0 & 0 & 1.0000 & 0.0000 \\
Taoyuan black & 74 & 41 & 127 & 15 & 0.7432 & 0.2568 \\
Yorkshire & 293 & & & & 0.3567 & 0.6433 \\
\hline
\end{tabular}

\section{DISCUSSION}

Protein phosphorylation, one of the most common and important means of protein modification after translation, was a common mechanism for life activity regulation that played an important role in the process of cellular signal transduction (Liang et al., 2012). Sixteen serine phosphorylation sites, 5 threonine phosphorylation sites and 2 tyrosine phosphorylation sites had been found in porcine GLP2R. These sites may played important roles in signal transduction of somatic cell and cell growth, differentiation, and other physiological processes.

Phylogenetic analysis of porcine GLP2R gene showed that pigs were close relatives to other mammals (such as Orcinus orca and Ovis aries) and relatively distant to reptiles (Chrysemys picta bellii) and birds (Falco peregrinus, Taeniopygia guttata). This result conformed to the general law of evolution. Taken together, these results suggested that the GLP2R gene was strongly conserved in the long-term evolution process, and had different species specificity. This suggested that it could play an important role in the process of biological growth and development.

We demonstrated that porcine GLP2R gene was expressed in 10 different tissues taken from the two pig breeds studied, and that expression levels were highest in longissimus dorsi muscle. In a previous study, porcine GLP2R expression levels were found to be significantly related to IMF, based on genome-wide association analysis (Luo et al., 2012).

Orskov et al. (2005) reported that in the digestive tract of non-ruminants, GLP2R mRNA was mainly expressed in the proximal small intestine, in particular in jejunum. Park et al. (2013) reported that cattle GLP2R mRNA was mainly expressed in the small intestine and colon tissue. In a study of mice, expression of GLP2R gene was detected in the duodenum, jejunum, ileum, and colon but not in the liver, lung, and kidney (Han et al., 2009). Differences between these studies may be due to such factors as animal age, as well as the different test methods used. 
Petersen et al. (2003) observed that GLP2R mRNA expression levels in small intestine gradually declined with increasing animal age; that is, the neonatal piglet GLP2R mRNA abundance was the highest, and then decreased significantly toward weaning age. In the current study, animals were 25 day old at sampling, and, with the exception of longissimus dorsi muscle, GLP2R mRNA expression levels were low overall. Age-related declines in expression levels may account for this observation.

RACE technique was adopted in the study to successfully clone porcine $G L P 2 R$, alongside bioinformatics methods to analyze the sequence and characterize its encoded protein. The results presented here laid the foundation for future studies to explore the functions of GLP2R. It is important for the meat industry to improve meat quality, in particular, the IMF content of pork. Most recent studies on IMF focused on the mechanism of lipogenesis (Morcuende et al., 2007; Zhao et al., 2009), and numerous candidate genes associated with IMF deposition had been identified (Cánovas et al., 2010; Serão et al., 2011; Tyra and Ropka-Molik, 2011). As mentioned, porcine GLP2R is significantly related to IMF in pork (Luo et al., 2012). In the current study, an SNP site was identified in intron 5, but further work is needed to confirm if this SNP is associated with IMF. These results raised the possibility of using molecular marker assistant (MAS) selection in porcine breeding.

\section{ACKNOWLEDGEMENTS}

Research supported by the National High Technology Research and Development Program of China (Grant \#2011AA\#1003 04) the Provincial National Science Foundation of Hunan (Grant \#13JJ1021); and the Key Foundation of Education Department in Hunan (Grant \#12A060).

\section{REFERENCES}

Burrin DG, Stoll B, Guan X, Cui L, et al. (2005). Glucagon-like peptide 2 dose-dependently activates intestinal cell survival and proliferation in neonatal piglets. Endocrinology 146: 22-32.

Cameron ND (1990). A Genetic and phenotypic parameters for carcass traits, meat and eating quality traits in pigs. Livest. Prod. Sc. 26: 119-135.

Cánovas A, Quintanilla R, Amills M and Pena RN (2010). Muscle transcriptomic profiles in pigs with divergent phenotypes for fatness traits. BMC Genomics 11: 372.

de Heer J, Pedersen J, Orskov C and Holst JJ (2007). The alpha cell expresses glucagon-like peptide-2 receptors and glucagon-like peptide-2 stimulates glucagon secretion from the rat pancreas. Diabetologia 50: 2135-2142.

Fernandez X, Monin G, Talmant A, Mourot J, et al. (1999). Influence of intramuscular fat content on the quality of pig meat - 1. Composition of the lipid fraction and sensory characteristics of $\mathrm{m}$. longissimus lumborum. Meat Sci. 53: 59-65.

Gao SZ and Zhao SM (2009). Physiology, affecting factors and strategies for control of pig meat intramuscular fat. Recent Pat. Food Nutr. Agric. 1: 59-74.

Gjerlaug-Enger E, Aass L, Odegård J, and Vangen O (2010). Genetic parameters of meat quality traits in two pig breeds measured by rapid methods. Animal 4: 1832-1843.

Grindflek E, Szyda J, Liu Z and Lien S (2001). Detection of quantitative trait loci for meat quality in a commercial slaughter pig cross. Mamm. Genome 12: 299-304.

Han W and Zou Y (2010). Progress in effects of glucagon like peptide 2 on gastrointestinal. Med. Recap. 16: 518-520.

Han W, Ma XJ, Zhu L, Gong DZ, et al. (2009). Effects of glucagon-like peptide-2 receptor on gastrointestinal mucosa and its receptor distribution in mice. Modern Hospital 9: 27-29.

Hsieh J, Longuet C, Maida A, Bahrami J, et al. (2009). Glucagon-like peptide-2 increases intestinal lipid absorption and chylomicron production via CD36. Gastroenterology 137: 997-1005.

Jiang RC, Jia G and Wang KN (2008). Effects of glucagon-like peptide 2 (GLP-2) on morphology proliferation function and enzyme activity of small intestinal epithelial cell of weaning pig in vitro. Chin. J. An. Nutrit. 6: 699-705.

Jiang Y, Jia G, Hui MD, Chen XL, et al. (2012). Effects of glucagon-like peptide-2 supplementation on expression of intestinal epithelial tight junction protein related genes in weaner piglets in vitro. Chin. J. An. Nutrit. 24: 1785-1789. 
Jin S, Guo X, Bao PJ, Niang CN, et al. (2013). Sequence analysis and study on the expression level of Dmrt7 gene in yak and cattle-yak testis. Sci. Agr. Sin. 46: 1036-1043.

Li X, Kim SW, Choi JS, Lee YM, et al. (2011). Investigation of porcine FABP3 and LEPR gene polymorphisms and mRNA expression for variation in intramuscular fat content. Mol. Biol. Rep. 37: 3931-3939.

Liang QJ, Wang PC and Bai YR (2012). Summarization on the research progress in protein phosphorylation. Sci. Technol. Review 30: 73-79.

Luo W, Cheng D, Chen S, Wang L, et al. (2012). Genome-wide association analysis of meat quality traits in a porcine Large White $\times$ Minzhu intercross population. Int. J. Biol. Sci. 8: 580-595.

Mo C, Zhong Y, Wang Y, Yan Z, et al. (2014). Characterization of glucagon-like peptide 2 receptor (GLP2R) gene in chickens: functional analysis, tissue distribution, and developmental expression profile of GLP2R in embryonic intestine. Domest. Anim. Endocrinol. 48: 1-6.

Moadebi S, Harder CK, Fitzgerald MJ, Elwood KR et al. (2007). Fluoroquinolones for the treatment of pulmonary tuberculosis. Drugs 67: 2077-2099.

Morcuende D, Estévez M, Ramírez R and Cava R (2007). Effect of the Iberian x Duroc reciprocal cross on productive parameters, meat quality and lipogenic enzyme activities. Meat Sci. 76: 86-94.

Orskov C, Hartmann B, Poulsen SS, Thulesen J, et al. (2005). GLP-2 stimulates colonic growth via KGF, released by subepithelial myofibroblasts with GLP-2 receptors. Regul. Pept. 124: 105-112.

Park CR, Moon MJ, Park S, Kim DK, et al. (2013). A novel glucagon-related peptide (GCRP) and its receptor GCRPR account for coevolution of their family members in vertebrates. PLoS One 8: e65420.

Petersen YM, Hartmann B, Holst JJ, Le Huerou-Luron I, et al. (2003). Introduction of enteral food increases plasma GLP-2 and decreases GLP-2 receptor mRNA abundance during pig development. J. Nut. 133: 1781-1786.

Qiu LP and Chen JH (2013). Research advance in mechanism of glucagon-like peptide-2. Med. Recap. 19: 240-242.

Serão NV, Veroneze R, Ribeiro AM, Verardo LL, et al. (2011). Candidate gene expression and intramuscular fat content in pigs. J. Anim. Breed. Genet. 128: 28-34.

Shin ED, Estall JL, Izzo A, Drucker DJ, et al. (2005). Mucosal adaptation to enteral nutrients is dependent on the physiologic actions of glucagon-like peptide-2 in mice. Gastroenterology 128: 1340-1353.

Suzuki K, Irie M, Kadowaki H, Shibata T, et al. (2005). Genetic parameter estimates of meat quality traits in Duroc pigs selected for average daily gain, longissimus muscle area, backfat thickness, and intramuscular fat content. J. Anim. Sci. 83: 2058-2065.

Tamura K, Peterson D, Peterson N, Stecher G, et al. (2011). MEGA5: Molecular Evolutionary Genetics Analysis using Maximum Likelihood, Evolutionary Distance, and Maximum Parsimony Methods. Mol. Biol. Evol. 28: 2731-2739.

Taylor-Edwards CC, Burrin DG, Matthews JC, McLeod KR, et al. (2010). Expression of mRNA for proglucagon and glucagonlike peptide-2 (GLP-2) receptor in the ruminant gastrointestinal tract and the influence of energy intake. Domest. Anim. Endocrinol. 39: 181-193.

Tyra M and Ropka-Molik K (2011). Effect of the FABP3 and LEPR gene polymorphisms and expression levels on intramuscular fat (IMF) content and fat cover degree in pigs. Livestock Sci. 142: 114-120.

Winer J, Jung CK, Shackel I and Williams PM (1999). Development and validation of real-time quantitative reverse transcriptasepolymerase chain reaction for monitoring gene expression in cardiac myocytes in vitro. Anal. Biochem. 270: 41-49.

Wood JD, Enser M, Fisher AV, Nute GR, et al. (2008). Fat deposition, fatty acid composition and meat quality: A review Meat Sci. 78: 343-358.

Wu YH, Zhu L, Zou Y, Gong DZ (2010). Present status of research on glucagon-like peptide 2. Progress in Physiology 41: 283-286.

Yazbeck R, Howarth GS and Abbott CA (2009). Growth factor based therapies and intestinal disease: is glucagon-like peptide-2 the new way forward? Cytokine Growth Factor Rev. 20: 175-184.

Yeku O and Frohman MA (2011). Rapid amplification of cDNA ends (RACE). Methods Mol. Biol. 703: 107-122.

Zhao SM, Ren LJ, Chen L, Zhang X, et al. (2009). Differential expression of lipid metabolism related genes in porcine muscle tissue leading to different intramuscular fat deposition. Lipids 44: 1029-1037. 